\title{
Selective occlusion of the hepatic artery and portal vein improves liver hypertrophy for staged hepatectomy
}

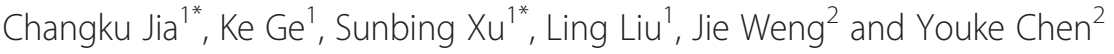

\begin{abstract}
Background: To evaluate the safety and feasibility of selective occlusion of the hepatic artery and portal vein (SOAP) for staged hepatectomy (SOAPS) in patients with hepatocellular carcinoma (HCC)

Methods: From December 2014 to August 2018, 9 patients with unresectable HCC were chosen to undergo SOAPS. SOAP without liver partition was performed in the first stage. The second stage was performed when future liver remnant (FLR) was equal to or bigger than $40 \%$ of the standard liver volume (SLV). The growth rate of FLR, perioperative outcomes, and survival data was recorded.

Results: In the first stage, all the 9 patients completed SOAP. Two cases received radiological interventional method and 7 cases received open operation. None of them developed liver failure and died following SOAP. After SOAP, FLR increased $145.0 \mathrm{ml}$ (115.0 to $210 \mathrm{ml}$ ) and $37.1 \%$ (25.6 to 51.7\%) on average. The average time interval between the two stages was 14.1 days (8 to 18 days). In the second stage, no in-hospital deaths occurred after SOAPS. One patient suffered from liver failure after SOAPS, and artificial liver support was adopted and his total bilirubin level returned to normal after postoperative day 35. The alpha-fetoprotein level of 8 patients reduced to normal within 2 months after SOAPS. Among 9 patients, 5 patients survived, 4 patients died of intrahepatic recurrence, lung metastasis, or bone metastasis. In the 5 survived cases, bone metastasis and intrahepatic recurrence were found in 1 patient, intrahepatic recurrence was found in another patient, and the remaining 3 patients were free of recurrence. The median disease-free survival time and overall survival time were 10.4 and 13.9 months, respectively.
\end{abstract}

Conclusion: SOAP can facilitate rapid and sustained FLR hypertrophy, and SOAPS is safe and effective in patients with unresectable HCC.

Keywords: Staged hepatectomy, Portal vein ligation, Hepatic artery ligation, Future liver remnant, Hepatocellular carcinoma

\section{Highlights}

1. SOAP can facilitate rapid and sustained FLR hypertrophy.

2. SOAPS is safe and effective in patients with unresectable HCC.

\footnotetext{
*Correspondence: Jiachk@126.com; xsbing2@163.com

'Department of Hepatobiliary Pancreatic Surgery, Affiliated Hangzhou First People's Hospital, Zhejiang University School of Medicine, Zhejiang Clinical Research Center of Hepatobiliary and Pancreatic Diseases, No. 261, Huansha Road, Hangzhou 310006, China

Full list of author information is available at the end of the article
}

\section{Background}

Liver resection, a curative therapy, is the most successful treatment for hepatocellular carcinoma (HCC) in appropriate stages [1]. The Barcelona Clinic Liver Cancer (BCLC) staging system was worldwide accepted. According to the BCLC system, the HCCs larger than $10 \mathrm{~cm}$ and/ or with portal vein tumor thrombus are not suggested to surgical treatment [2]. But the shortcoming of the BCLC system might keep many patients off benefiting from liver resection when the lesions were staged as intermediate (B) and advanced (C). A lot of studies [3-5] reported favorable outcomes of liver resection compared with the nonsurgical options. Based on the previous evidences, some radical opinions were proposed that liver resection could

(c) The Author(s). 2019 Open Access This article is distributed under the terms of the Creative Commons Attribution 4.0 International License (http://creativecommons.org/licenses/by/4.0/), which permits unrestricted use, distribution, and 
be offered to any HCCs $>5 \mathrm{~cm}$, as long as negative margin and appropriate liver function could be achieved [6]. Commonly, the liver function might be the key limiting factor for liver resection, particularly the postoperative liver function. Liver function is based on adequate liver volume. For HCCs, residual volume of $20 \%$ was acceptable in normal liver, but as much as $30 \%$ in chronic liver disease without cirrhosis and $40 \%$ in Child A cirrhosis were required for a safe liver resection [7]. Insufficient future liver remnant (FLR) would result in liver failure (LF) which is a fatal complication. When facing insufficient FLR, transcatheter arterial chemoembolization (TACE) is an alternative [8]. However, the incidence of local tumor recurrence after TACE is higher than that reported after surgical resection $[8,9]$. Moreover, the long-term survival after TACE was much less than that after hepatectomy [5]. Thus, resection of large HCCs, which were defined as inoperable previously, became another option. In 1990, Makuuchi et al. [10] reported FLR hypertrophy achieved by portal vein embolization (PVE), which was known as the first-stage operation of conventional staged hepatectomy (CSH). The CSH extended the surgical indication for unresectable hepatic cancer. However, the major disadvantage of $\mathrm{CSH}$ was the long time interval between stages. Following portal vein ligation (PVL) or PVE, a $40 \%$ volume increase of FLR took at least 3 to 8 weeks [11]. Moreover, approximately $30 \%$ of patients who underwent $\mathrm{CSH}$ could not complete the second stage due to low hypertrophy efficiency [11].

In 2012, Schnitzbauer et al. [12] described a novel approach-associating liver partition and portal vein ligation for staged hepatectomy (ALPPS), which resulted in a hepatic volume increase of $47-93 \%$ in 6-14 days [13]. The shorter time interval of ALPPS caused a higher completion rate for staged hepatectomy, as high as 95$100 \%$ [13]. However, it was unacceptable that ALPPS unfortunately led to a morbidity rate of $68 \%$ and a mortality rate of $14 \%$ [12].

The underlying mechanisms behind the rapid growth of FLR were postulated that the effect relied on the discontinuation of portal circulation after PVE and transection between the normally perfused and deportalized liver parts $[14,15]$. Based on these studies, we hypothesized that the FLR hypertrophy would be promoted after redistributions of arterial circulation and portal circulation. In the present study, we introduce a novel and safe method of selective occlusion of the hepatic artery (HA) and portal vein (PV) for staged hepatectomy (SOAPS) which balances surgical safety and growth effectiveness and consists of two stages. In the first stage, selective occlusion of the hepatic artery and portal vein (SOAP) without liver partition is performed. There are two approaches that could be selected to conduct SOAP, which are interventional method and open surgery. The former is preferred along with patient's consent and technical feasibility. In the second stage, right trisectionectomy, right hemihepatectomy, or left trisectionectomy are performed respectively if the FLR has increased sufficiently.

\section{Methods \\ Patients}

Between December 2014 and August 2018, 9 consecutive patients in our center underwent this novel procedure, including 6 males and 3 females. Their average age was 43.9 years. All patients carried overexpressed alphafetoprotein (AFP) in serum and were diagnosed with HCC. The average tumor diameter was $128.4 \mathrm{~mm}$. Five patients had satellite lesions and two patients had a cancer embolus in the right PV branch. The average FLR volume (FLRV) was $400.4 \mathrm{~mL}$, and the ratio of FLRV to the standard liver volume (SLV) was $32.7 \%$ on average before the first stage. The SLV was estimated using the method reported by Urata et al. [16]. As all patients are suffering from chronic hepatitis B, at least $40 \%$ of SLV was considered as sufficient for the FLR. Patients' characteristics are summarized in Table 1. According to tumor size and location, 6 patients were scheduled to right hemihepatectomy, 2 patients were right trisectionectomy, and 1 patient was left trisectionectomy. The planned surgeries were listed in Table 1 . The terminology of liver resections was according to the Brisbane 2000 Nomenclature of Liver Anatomy and Resections [17].

This study was approved by the ethics committee of our centers (2014KYNo.017). All patients were told the purpose of this study and signed the informed consents. The Child-Pugh Score was adopted for preoperative liver function evaluation and combining Child-Pugh Score and FLRV for predicting postoperative liver dysfunction [18]. The comprehensive complication index (CCI) was adopted for evaluating postoperative morbidity [19]. Postoperative LF was assessed by 50-50 criteria [20]. The FLRV was evaluated by contrast-enhanced computed tomography (CT) nearly before SOAP and a week after SOAP, if the FLRV did not grow to an enough volume, the additional CT scan would be done a week later. Volumetric data were obtained from the portal phase image. We calculated FLRV from CT film by the method reported by Yoo et al. [21]. The gallbladder and hepatic veins were defined as the borderlines among different liver lobes. The time interval between the two stages was defined as below: The terminal point of "time interval" was the time of the satisfactory CT scan (the "second" CT scan), which contained a sufficient FLRV after SOAP. Then, the planned hepatectomy would be done nearly after the time of this CT scan. The starting point of "time interval" was the time of SOAP. The "first" CT scan would be done nearly before the time of 
Table 1 Characteristics of patients and tumor

\begin{tabular}{|c|c|c|c|c|c|c|c|}
\hline Variable & Age (years) & Gender & Tumor diameter (mm) & $\operatorname{AFP}(\mathrm{ng} / \mathrm{ml})$ & Child's score & Planned procedure & $\begin{array}{l}\text { Initial FLRV (ml), } \\
\% \text { of the SLV }\end{array}$ \\
\hline Patient 1 & 23 & Female & 114 & $>2000$ & 5 & Right trisectionectomy & $421,32.2 \%$ \\
\hline Patient 2 & 42 & Female & 89 & $>2000$ & 5 & Right hemihepatectomy & $312,28.7 \%$ \\
\hline Patient 3 & 46 & Male & 123 & 582.7 & 5 & Right hemihepatectomy & $350,25.0 \%$ \\
\hline Patient 4 & 54 & Male & 155 & 557.9 & 6 & Right hemihepatectomy & $511,37.9 \%$ \\
\hline Patient 5 & 51 & Male & 130 & 1994.4 & 6 & Left trisectionectomy & $505,35.8 \%$ \\
\hline Patient 6 & 52 & Female & 95 & 227.5 & 6 & $\begin{array}{l}\text { Laparoscopic right } \\
\text { hemihepatectomy }\end{array}$ & $456,37.7 \%$ \\
\hline Patient 7 & 41 & Male & 205 & $>2000$ & 6 & Right trisectionectomy & $306,27.3 \%$ \\
\hline Patient 8 & 44 & Male & 130 & 1290.4 & 5 & Right hemihepatectomy & $385,35.4 \%$ \\
\hline Patient 9 & 42 & Male & 115 & 850.8 & 6 & $\begin{array}{l}\text { Laparoscopic right } \\
\text { hemihepatectomy }\end{array}$ & $358,34.5 \%$ \\
\hline
\end{tabular}

AFP the level of serum alpha-fetoprotein before operation, FLRV the volume of the future liver remnant, Initial FLRV, the FLRV before the first-stage operation, SLV standard liver volume

SOAP, commonly less than a week. The growth rate of FLRV = (FLRV of the "second" CT scan-FLRV of the "first" CT scan)/time interval. The FLRV change was expressed as growth range, which was calculated via the formula: growth range $=($ FLRV after operation-FLRV before operation)/FLRV before operation $\times 100 \%$.

\section{Surgical and interventional procedure}

In the current study, SOAPS consisted of two stages. SOAP without liver partition was performed in the first stage. Hepatectomy was then performed in the second stage if the FLRV increased sufficiently. The two-stage operations were sequentially performed in one hospital stay.

In the first stage, 7 patients underwent a surgical procedure and 2 patients underwent an interventional procedure. The latter procedure was preferred in this study. But the performance of the interventional procedure was based on the patient's consent and the feasibility assessment. The assessment was from the discussion between surgeons and radiologists according to the preoperative CT film and ultrasonography. If the path of PV puncture was too closed to or covered by the tumor, the percutaneous PVE became impossible. The 9 patients were treated by the same chief surgeon, but in the two different centers. The patients 1-5 received treatment at the First Affiliated Hospital of Hainan Medical College. The patients 6-9 were treated at the Affiliated Hangzhou First People's Hospital, Zhejiang University School of Medicine. The patient 6 and patient 9 were the only two patients who underwent interventional first-stage procedure.

For the patients who underwent surgical procedure, a laparotomy using a right subcostal incision was performed. The hepatic hilar region and Glisson's capsule were separated to identify the main branches of the PV and HA. The main branches of the PV and HA were identified as ligation candidates. The right PV, left medial branch of PV, and HA were ligated in the patients scheduled to undergo right trisectionectomy in the second stage (Fig. 1). The right PV and right posterior or anterior branch of HA were ligated in the patients scheduled to undergo right hemihepatectomy in the second stage. Whether the right posterior or anterior branch of the HA was ligated was determined by the location of the tumor and the portion of normal liver tissue. The arterial branch mainly feeding the tumor-free lobe was ligated, and the arterial branch mainly feeding the tumor-bearing lobe was selectively reserved (Fig. 2). The left PV, right anterior branch of PV, and right anterior branch of HA were ligated in the patients scheduled to undergo left trisectionectomy in the second stage. All operations were performed without parenchymal transection. No hepatic ligaments were dissected and no drainage tube placement was carried out in this stage of the operation.

In the first stage, two patients were performed interventional therapies, including concomitant embolization of right PV and right anterior branch of HA. Candidate occluded vasculature is summarized in Table 2 .

The selective transarterial embolization (TAE) and PVE were performed as the methods described in the previous studies $[21,22]$. The selective TAE was conducted under local anesthesia and fluoroscopic guidance. After the tip of the catheter was placed selectively in the right anterior branch of HA, iodinized oil was injected under fluoroscopic control, followed by embolization with gelatin-sponge particles. PVE was performed after TAE under general anesthesia in the same day. Under ultrasonographic guidance, right PVE was achieved by using coils and gelatin-sponge particles.

In the second stage, a bilateral subcostal incision via the original incision in the first stage was made during 

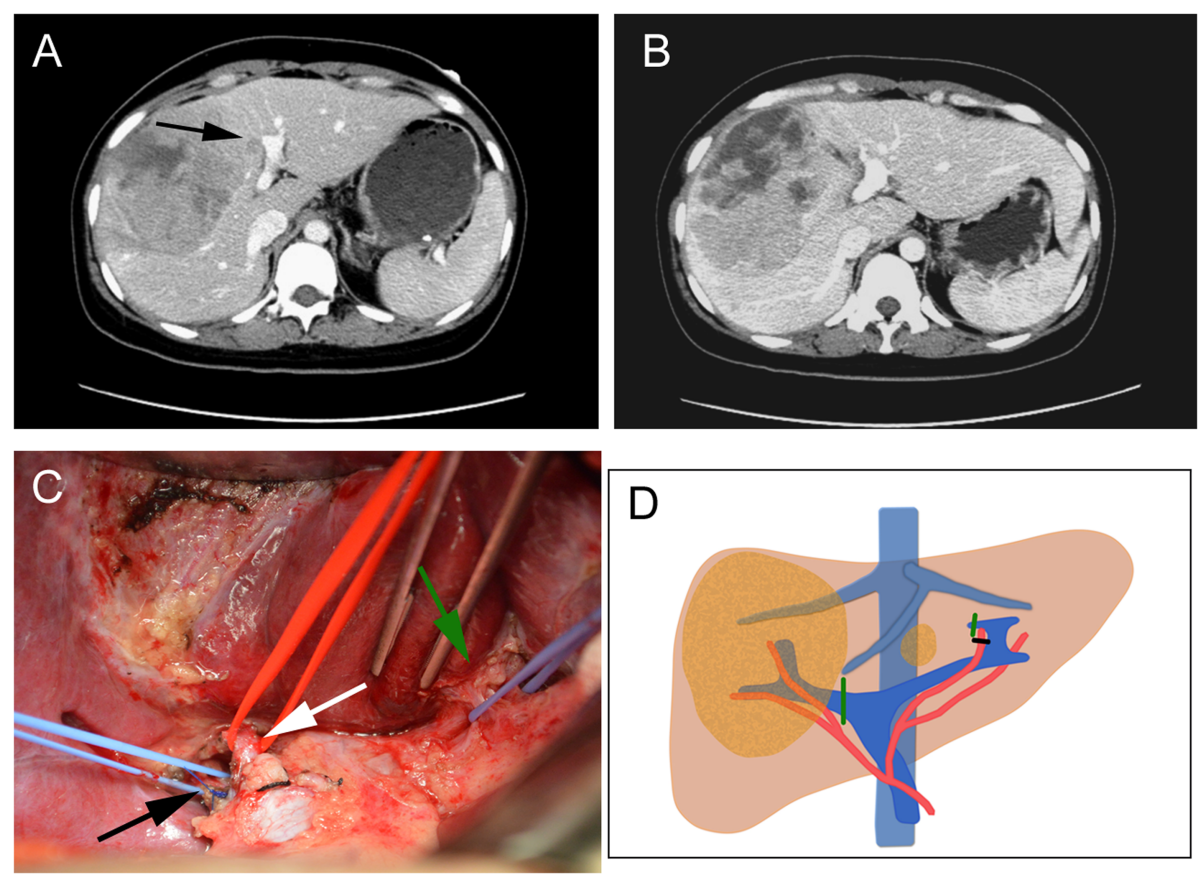

Fig. 1 Preoperative findings and operative schema of patient 1 during the first stage. a Preoperative contrast CT revealed a huge hepatocellular carcinoma with a satellite lesion (arrow) in the right and left medial lobe of liver. $\mathbf{b}$ The contrast CT showed an obvious volume increase of left lateral lobe on the postoperative day 12. c After the extraparenchymal separation, the main branch of right PV (black arrow), the main branch of right HA (white arrow), and the vascular bundle (including PV and HA) feeding to left medial lobe (green arrow) were exposed. $\mathbf{d}$ Operative schema of the first stage. Both main branch of right PV and PV feeding to left medial lobe were ligated (green line); the main branch of HA feeding to segment 4 was ligated (black line).

laparotomy in 8 patients. The planned hepatectomy was then performed using an anterior approach as reported in previous studies $[23,24]$. Laparoscopic right hemihepatectomy using an anterior approach was performed in 2 patients during the second stage.

\section{Statistical analysis}

All analyses were performed using SPSS v20.0. Diseasefree survival time (DFS) and overall survival time (OS) were estimated using the Kaplan-Meier survival curves. Median DFS and median OS were calculated from the date of diagnosis for patients. Patients were followed up to death, or they were censored on December 1, 2018. The CCI was calculated by the online calculator (http:// www.assessurgery.com).

\section{Results}

In the first stage of SOAP, 7 patients underwent selective ligation and 2 patients underwent successful interventional embolization of HA and PV. For those 7 patients underwent surgical procedure, the average operation time was $104 \mathrm{~min}(80-130 \mathrm{~min})$ and the average blood loss was $108 \mathrm{~mL}(50-150 \mathrm{~mL})$. All patients suffered from mild fever below $39^{\circ} \mathrm{C}$ after postoperative day (POD) 3-4 and were cured by noninvasive cooling techniques (CCIs: 8.7). Generally, the ice packs or luke-warm water baths would be employed when the temperature was under $38.5{ }^{\circ} \mathrm{C}$; otherwise, cooled intravenous fluids might be considered. Patient 4 had mild pleural effusion in the right chest cavity (CCI: 27.6), who had mild oxygen desaturation ranging from 94 to $96 \%$ according to the fingertip pulse oximeter without oxygen inhalation. Although there was no difficulty breathing and chest pain, the oxygen saturation returned to above $98 \%$ after extracting about $350 \mathrm{ml}$ fluid through a puncture tube. Serum alanine transaminase (ALT) and serum total bilirubin (TBiL) were both markedly elevated after the first-stage procedure, while gradually returned to normal after reaching peak values. ALT reached a peak value of $1639.9 \mathrm{U} / \mathrm{L}(187-4620 \mathrm{U} / \mathrm{L})$ on average after POD $1-3$, and TBiL reached a peak value of $31.2 \mu \mathrm{mol} / \mathrm{L}(21.3-39.6 \mu \mathrm{mol} / \mathrm{L})$ on average after POD 17 (Table 2). None of the patients developed LF and no deaths occurred. FLRV increased by $145.0 \mathrm{~mL}$ on average at a rate of $14.7 \mathrm{~mL} /$ day. The average ratio of FLRV to SLV increased from 32.7 to $45.1 \%$ after SOAP. The average time interval between the two stages was 14.1 days (8-18 days). The growth data was listed in Table 3.

In the second stage, all patients completed the planned hepatectomy. The average operation time was $260 \mathrm{~min}$ (180-420 min), and the average blood loss was $640 \mathrm{~mL}$ (200-1300 mL). All postoperative pathological diagnoses were HCC. Of these 9 cases, 3 cases were histologically 

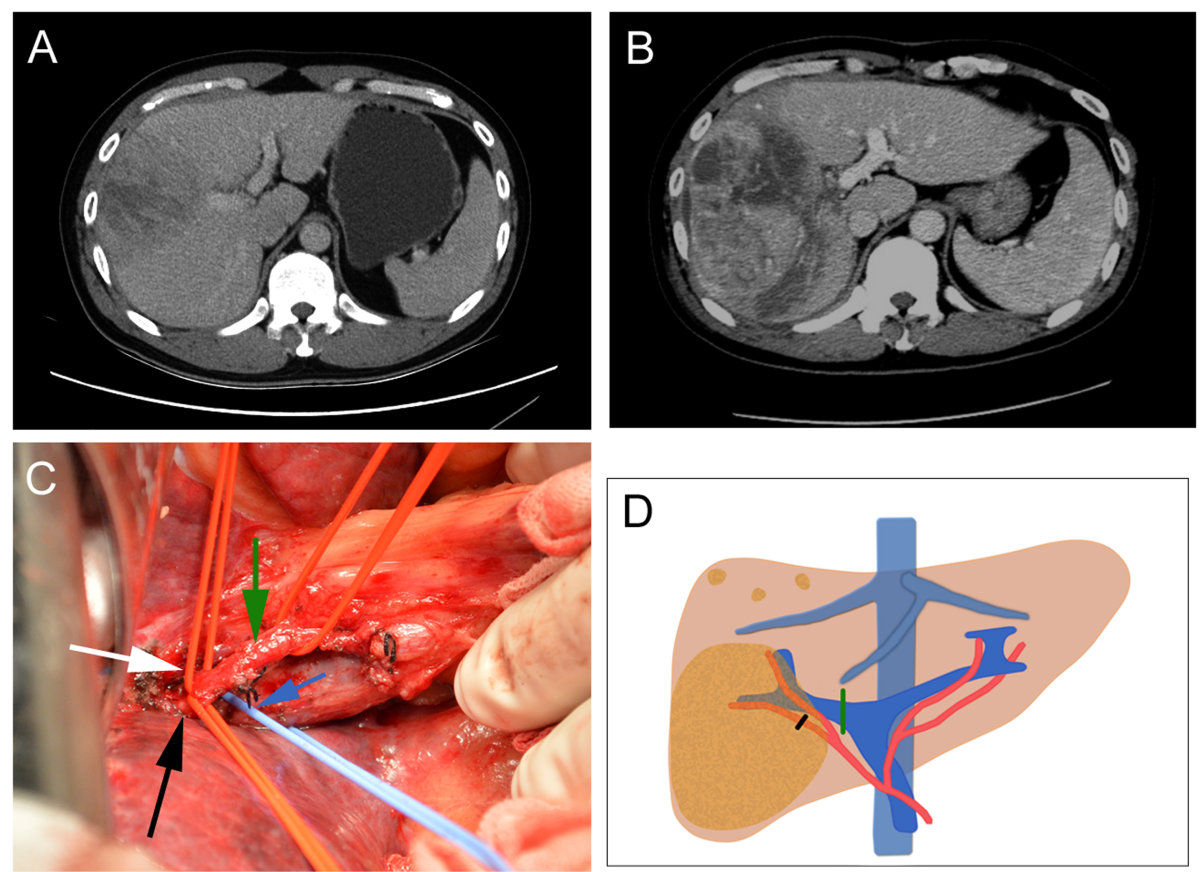

Fig. 2 Preoperative findings and operative schema of patient 3 during the first stage. a Preoperative contrast CT revealed a huge hepatocellular carcinoma in the right lobe of liver. $\mathbf{b}$ The contrast CT showed an obvious volume increase of the future liver remnant on the postoperative day 13. c After the extraparenchymal separation, the main branch of right PV (blue arrow), the main branch of right HA (green arrow), the secondary arterial branches of the right anterior lobe (white arrow), and the right posterior lobe (black arrow) were exposed. $\mathbf{d}$ Operative schema of the first stage. The main branch of right PV was ligated (green line); the arterial branch of the right posterior lobe was ligated (black line)

identified as highly differentiated, 4 cases were moderately differentiated and 2 cases were poorly differentiated. There were 3 patients' liver capsules involved by tumors. All the surgical margins were negative $(>1$ $\mathrm{mm})$. Vessel cancer emboli were found in 7 cases. No in-hospital deaths occurred after SOAPS. Patient 4 developed LF after SOAPS and artificial liver support was adopted for him and his TBiL was returned normal after POD 35 (CCI: 43.3). Intra-abdominal collection was found at POD 5 with fever in patient 7 , which was drained by abdominal catheterization guided by ultrasound and was diagnosed with bile leakage (CCI: 27.6). All patients suffered from mild fever below $39{ }^{\circ} \mathrm{C}$ after POD $3-5$ and were cured by noninvasive cooling

Table 2 Surgical or interventional procedures for first-stage operation, outcomes post first-stage operation

\begin{tabular}{|c|c|c|c|c|c|c|}
\hline Variable & PV branches occluded & HA branches occluded & Procedure & Peak ALT (U/L) & Peak TBiL ( $\mu \mathrm{mol} / \mathrm{L})$ & $\mathrm{CCl}$ \\
\hline Patient 1 & $\begin{array}{l}\text { Right branch, left } \\
\text { medial branch }\end{array}$ & Left medial branch & Right trisectionectomy & 187 & 22.2 & 8.7 \\
\hline Patient 2 & Right branch & Right posterior branch & Right hemihepatectomy & 846.6 & 21.3 & 8.7 \\
\hline Patient 3 & Right branch & Right posterior branch & Right hemihepatectomy & 4620 & 39.6 & 8.7 \\
\hline Patient 4 & Right branch & Right posterior branch & Right hemihepatectomy & 676.9 & 35.5 & 27.6 \\
\hline Patient 5 & $\begin{array}{l}\text { Left branch, right } \\
\text { anterior branch }\end{array}$ & Right anterior branch & Left trisectionectomy & 1868.8 & 37.4 & 8.7 \\
\hline Patient 6 & Right branch & Right anterior branch & $\begin{array}{l}\text { Laparoscopic right } \\
\text { hemihepatectomy }\end{array}$ & 1034 & 29.9 & 8.7 \\
\hline Patient 7 & $\begin{array}{l}\text { Right branch, left } \\
\text { medial branch }\end{array}$ & Left medial branch & Right trisectionectomy & 1170 & 39 & 8.7 \\
\hline Patient 8 & Right branch & Right posterior branch & Right hemihepatectomy & 1778.8 & 38.7 & 8.7 \\
\hline Patient 9 & Right branch & Right anterior branch & $\begin{array}{l}\text { Laparoscopic right } \\
\text { hemihepatectomy }\end{array}$ & 1156.3 & 28.5 & 8.7 \\
\hline
\end{tabular}

$P V$ portal vein, $H A$ hepatic artery, ALT serum alanine transaminase, TBiL serum total bilirubin, $C C l$ the comprehensive complication index 
Table 3 The growth data of the hepatic remnant after SOAP and the short-term and long-term outcomes after the second-stage operation

\begin{tabular}{|c|c|c|c|c|c|c|c|c|c|}
\hline Variable & $\begin{array}{l}\text { Terminal FLRV }(\mathrm{ml}), \% \text { of } \\
\text { the SLV }\end{array}$ & $\begin{array}{l}\text { Growth rate }(\mathrm{ml} / \\
\text { day) }\end{array}$ & $\begin{array}{l}\text { Time interval } \\
\text { (days) }\end{array}$ & $\begin{array}{l}\text { Growth range } \\
(\%)\end{array}$ & $\mathrm{CCl}$ & $\begin{array}{l}\mathrm{AFP}^{*}(\mathrm{ng} / \\
\mathrm{ml})\end{array}$ & $\begin{array}{l}\text { LOS* }^{*} \\
\text { (days) }\end{array}$ & $\begin{array}{l}\text { DFS } \\
\text { (months) }\end{array}$ & $\begin{array}{l}\text { OS (months), } \\
\text { status }\end{array}$ \\
\hline $\begin{array}{l}\text { Patient } \\
1\end{array}$ & $550,53.5 \%$ & 18.4 & 12 & 30.60 & 8.7 & 15.9 & 19 & 4 & 9.2 , dead \\
\hline $\begin{array}{l}\text { Patient } \\
2\end{array}$ & $456,41.9 \%$ & 20.6 & 8 & 46.20 & 8.7 & 18.1 & 9 & $>40.2$ & $\begin{array}{l}\text { 40.2, alive } \\
\text { without disease }\end{array}$ \\
\hline $\begin{array}{l}\text { Patient } \\
3\end{array}$ & $531,37.7 \%$ & 16.5 & 13 & 51.70 & 43.3 & 4.7 & 12 & 7 & 13.8 , dead \\
\hline $\begin{array}{l}\text { Patient } \\
4\end{array}$ & $642,49.0 \%$ & 10.9 & 15 & 25.60 & 8.7 & 8.5 & 26 & 3.6 & 9.5, dead \\
\hline $\begin{array}{l}\text { Patient } \\
5\end{array}$ & $715,54.1 \%$ & 25.8 & 17 & 41.60 & 8.7 & 9.9 & 13 & 6.2 & $\begin{array}{l}\text { 20.8, alive with } \\
\text { disease }\end{array}$ \\
\hline $\begin{array}{l}\text { Patient } \\
6\end{array}$ & $581,43.8 \%$ & 10.4 & 15 & 27.40 & 8.7 & 3.2 & 12 & $>13.3$ & $\begin{array}{l}\text { 13.3, alive } \\
\text { without disease }\end{array}$ \\
\hline $\begin{array}{l}\text { Patient } \\
7\end{array}$ & $420,37.8 \%$ & 9 & 18 & 37.70 & 27.6 & 289.2 & 22 & 2.2 & 14.5, dead \\
\hline $\begin{array}{l}\text { Patient } \\
8\end{array}$ & $516,45.6 \%$ & 10.9 & 13 & 34.00 & 8.7 & 14.8 & 14 & 6.5 & $\begin{array}{l}\text { 13.5, alive with } \\
\text { disease }\end{array}$ \\
\hline $\begin{array}{l}\text { Patient } \\
9\end{array}$ & $498,42.7 \%$ & 10 & 16 & 39.10 & 8.7 & 19.3 & 18 & $>10.5$ & $\begin{array}{l}\text { 10.5, alive } \\
\text { without disease }\end{array}$ \\
\hline
\end{tabular}

techniques described above (CCIs: 8.7$)$. The mean length of hospital stay after SOAPS was 16.1 days (9-26 days). The AFP level in 8 patients reduced to normal within 2 months after SOAPS. Of these 9 patients, 4 patients died of intrahepatic recurrence, lung metastasis, or bone metastasis. Five of them survived when censored on December 1, 2018, and the longest survival time was 40.2 months. Among the 5 survived cases, bone metastasis and intrahepatic recurrence were found in 1 patient 6.2 months after SOAPS; intrahepatic recurrence was found in another patient 6.5 months after SOAPS, and the remaining 3 patients were without recurrence. The DFS was 10.4 months, and the OS was 13.9 months. In this study, Sorafenib-the molecular targeted anti-tumor drug used for HCC, was given to the patients with metastasis or recurrence. The short-term and long-term outcomes were listed in Table 3.

\section{Discussion}

For large HCCs, a sufficient resection margin is an independent protective factor for prognosis [25]. In addition, anatomic liver resection, rather than non-anatomic liver resection, is essential for long-term survival [26, 27]. Of note, complete anatomic hepatectomy for a large HCC commonly requires extensive liver resection. However, the inadequacy of FLRV has become an intractable clinical problem for hepatectomy. The incidence of LF after major hepatectomy ranged from 1.2 to $32.0 \%$, which was related to $80 \%$ of postoperative mortality $[28,29]$. Small
FLRV was an independent predictor for postoperative LF [29]. Another important parameter was FLR function, which was limited by the underlying liver diseases such as cirrhosis and steatosis [30]. Thus, the requirement of FLRV could be relaxed in a healthy liver but must high as $40 \%$ of total liver volume (TLV) in cirrhosis [7, 29]. In our study, SLV was adopted to estimate the actual TLV, which was due to the followed reasons. First, the TLV had to be calculated from CT film after removing the tumor volume. However, the shape of tumor was not always regular, which would influence the accuracy of calculation. The error would be further enlarged with the appearance of satellite lesions. Second, SLV was estimated from body surface area, which was not influenced by the underlying liver disease and much closer to a healthy liver [31]. Adoption of FLRV/SLV ratio but not FLRV/TLV ratio actually raised the surgical criteria, because the TLV would be reduced due to liver disease such as cirrhosis [32, 33].

PVE, known as the first-stage operation of CSH, has a long time interval between treatment stages and that may elicit tumor progression. Moreover, approximately $30 \%$ of patients who underwent PVE could not accomplish the second stage of the operation owing to low hypertrophy efficiency [11]. For ALPPS, although it induces rapid hypertrophy of the FLR and cuts down the time interval between treatment stages, it unexpectedly results in high morbidity and mortality [12, 13, 34-36]. Hence, several modified procedures of the first stage 
were proposed to overcome the disadvantages of $\mathrm{CSH}$ and ALPPS. The liver splitting of ALPPS was the main concern about higher postoperative morbidity [37]. In case of total parenchymal transection, there were several variations of liver splitting, such as partial splitting and in situ splitting by tourniquet compression, radiofrequency ablation, or microwave ablation [38]. The former was so-called partial-ALPPS combining partial parenchymal transection and PVE in stage 1. Petrowsky et al. [39] reported that the partial liver splitting between $50 \%$ and $80 \%$ of total liver transection surface could achieve a comparable hypertrophy with APPPS (median 60\% vs. $61 \%)$, and an absolutely lower severe complication rate ( $0 \%$ vs. $33 \%$ ), but only one out of 24 patients was diagnosed of HCC. For HCC, Chan et al. [40] reported that partial-ALPPS could not gain as faster hypertrophy as ALPPS (17.5 vs. $31.2 \mathrm{~mL} /$ day). The tourniquet-ALPPS replaced the liver splitting with a tourniquet bound 1$\mathrm{cm}$ deep in the surface around the liver transection line. However, the $64 \%$ morbidity and $9 \%$ mortality made this improvement unsatisfactory [41]. The first-stage procedures with radiofrequency ablation or microwave ablation were somewhat similar, which gained rapid hypertrophy but lower morbidity compared with ALPPS [42]. A recent randomized controlled trial (REBIRTH trial) of PVE versus ALPPS assisted with radiofrequency (RALPPS) reported that RALPPS could trigger a much faster hypertrophy and comparable morbidity compared with PVE [43]. Even ALPPS was reported to have a comparable surgical safety as PVE by a recent randomized controlled trial (Ligro trial) [44], which was completely opposite to the conclusions of many recent meta-analyses [45, 46]. However, most of the samples of these two randomized controlled studies were colorectal liver metastases. Thus, whether the conclusions remained stable for HCC was unclear. Guiu et al. [47] developed a novel procedure with simultaneous ipsilateral hepatic vein embolization and PVE, so-called liver venous deprivation technique, which resulted in a mean degree of hypertrophy of $12.7 \%$ after mean 23 days. Out of 7 patients, the only patient with HCC gained a growth rate of $12.2 \mathrm{~mL} /$ day in this study. However, sequential portal and hepatic vein embolization revealed liver hypertrophy was very slow in some patients with cirrhosis or HCC $[48,49]$.

Herein, we introduce SOAPS-a novel and safe method with two-stage hepatectomy, which balances surgical safety and growth effectiveness. The HA and PV were selectively ligated or embolized without parenchymal transection and hepatic ligament dissection in the first stage. A drainage tube was even not needed in the first stage. Therefore, complications were significantly decreased compared with ALPPS, such as abdominal bleeding, adhesions, and bile leakage [38]. And even the oncological safety would be improved as the classical approach of ALPPS was criticized for its "all-touch" defect [50]. Additionally, no postoperative mortality occurred both in the first and second stage. SOAP induced satisfactory hypertrophy of the FLR. Previous evidences $[46,51]$ showed that the kinetic growth rate was 14.4$32.7 \mathrm{~mL} /$ day for ALPPS and $2.42-4.4 \mathrm{~mL} /$ day for $\mathrm{CSH}$, and the time to reach a sufficient FLRV was 6-18 days for ALPPS and 20-168.8 days for CSH. In our study, FLR increased in all patients after SOAP and the FLRV increased by $145.0 \mathrm{~mL}$ on average. The average growth rate was $14.7 \mathrm{~mL} /$ day. The growth rate after SOAP was comparable to ALPPS and was much faster than CSH. Most importantly, considerable hypertrophy was achieved without liver partition.

Although with a shorter follow-up period, SOAPS had achieved a comparable survival result with ALPPS. D'Haese et al. [52] reported that the median OS was 5.9 months and the median DFS was 5.1 months in 35 patients with intermediate-stage HCC after ALPPS. In our study, the shortest DFS was 2.2 months and the longest DFS was observed in patient 2 , who had no sign of recurrence during the follow-up period (40.2 months). The median DFS was 10.4 months, and 3 patients were alive without disease. Besides, the median OS was 13.9 months in our study. A recent study [5] from a single center in China reported that the HCC patients (tumor diameter range from 6 to $31 \mathrm{~cm}$ ) after ALPPS gained the 1-year OS as much as $64.2 \%$, which was similar to our result (6 out of 9 patients). But their study [5] complied with a $91.1 \%$ uncompleted rate and a $11.1 \%$ 90-day mortality, which did not occur in our relatively small size study.

With regard to the mechanism of liver hypertrophy after the first stage of SOAP, we found that besides the reported PV blood redistribution, HA blood redistribution was one of the mechanisms of liver hypertrophy. Particularly, it was observed in patient 4 who had a cancer embolus in right PV which caused total obstruction of right PV and blood redistribution to left PV before SOAP. Even though, FLR of the patient still increased adequately after SOAP. As well as the results of previous studies, sequential PVE and TACE had been successfully performed for HCC and gained a significant liver hypertrophy $[21,22,53,54]$.

Hypoxia-enhanced invasiveness is a major concern in HA occlusion [55]. Massive necrosis of the tumor is still an alarming event after PVE plus HA ligation for large HCCs [56]. Thus, occlusion of HA was limited to one lobe (right posterior branch, right anterior branch, or left medial branch) in the SOAP. To prevent tumor hypoxia, necrosis, and tumor lysis syndrome, the arterial branch mainly feeding the tumor-free lobe was occluded and the arterial branch mainly feeding the tumor-bearing lobe was selectively reserved [57]. Therefore, the effectiveness of FLR hypertrophy and surgical safety was balanced. 
Concomitant occlusion of candidate vasculature by a transcatheter endovascular technique is less invasive than that of a surgical procedure. However, interventional techniques are not always appropriate in all cases. In the current study, PV and HA branch in the left medial lobe were occluded in patients who underwent right trisectionectomy. The vessel branches of left medial lobe are too tiny and various to percutaneously and transhepatically catheterize and embolize. Hence, interventional or surgical techniques should be individualized in different patients. Another reason was that when the large tumor located closed to or covered the path of puncture, the PVE became unsafe and impossible. Removing the satellite lesions at the first stage was a good choice for most HCCs, but the removing was not suitable for any cases. In our cases series, the tumor size was large on average. As reported by several studies [58, 59], the risk of tumor rupture increased with the increase of tumor size, and the fatal complications including liver failure after rupture were as high as $12-42 \%$. Most of the satellite lesions in our cases were closed to the main tumor or deep in the liver or near the important intrahepatic structures, resection, or ablation of which were not easy and oncologically safe.

As a case series study, relatively small sample size was a major limitation of this study. Fortunately, the results of the 9 patients revealed highly consistency. As the sample size accumulated, the reliability of the conclusion might be more stable. Second, the first-stage operations of our cases showed a degree of inconsistency. As mentioned above, the interventional technique was not suitable for any cases. Open surgery was given to 7 patients and interventional procedure was given to last 2 patients. Although they were the different routes to the same summit, the stability of results would reduce to a certain extent. In fact, the interventional approach would be the major method for SOAP, because of its minimal invasiveness. However, the surgical approach (open or laparoscopy) will not disappear, which will be optional when the interventional approach facing technical obstacles. Reducing the trauma of the operation is another focus. Thus, the minimally invasive methods such as laparoscopy and robot-assisted operation might be applied for the selected patients in the future.

\section{Conclusion}

SOAP can facilitate rapid and sustained FLR hypertrophy. SOAPS is safe and effective in patients with unresectable HCC.

\section{Authors' contributions}

Jia CK, as the chief surgeon, performed the operation; Jia CK and Xu SB designed the study; Ge K and Liu L collected the data and did statistical analysis; Jia CK and Xu SB wrote the manuscript; Jia CK, Weng J, and Chen YK revised the manuscript. All authors read and approved the final manuscript.

\section{Funding}

This study was supported by grant from the Application Research and Demonstration \& Promotion of Hainan Province (No. ZDXM2014074), the Medical Science and Technology Project of Zhejiang Province (No. 2017KYB521), and the Key Project of Medical Science and Technology Program of Hangzhou Health and Family Planning Commission (No. 2018Z01).

Availability of data and materials

Data will be made available by the authors on request.

Ethics approval and consent to participate

The study was approved by the ethics committee of the Affiliated Hangzhou First People's Hospital, Zhejiang University School of Medicine.

Consent for publication

The study was undertaken with the patient's consent.

\section{Competing interests}

The authors declare that they have no competing interests.

\section{Author details}

${ }^{1}$ Department of Hepatobiliary Pancreatic Surgery, Affiliated Hangzhou First People's Hospital, Zhejiang University School of Medicine, Zhejiang Clinical Research Center of Hepatobiliary and Pancreatic Diseases, No. 261, Huansha Road, Hangzhou 310006, China. ${ }^{2}$ Department of Hepatobiliary Pancreatic Surgery, The First Affiliated Hospital of Hainan Medical College, Haikou 570102, China.

Received: 15 March 2019 Accepted: 10 September 2019

Published online: 07 October 2019

\section{References}

1. Schlachterman A, Craft WW Jr, Hilgenfeldt E, Mitra A, Cabrera R. Current and future treatments for hepatocellular carcinoma. World J Gastroenterol. 2015; 21:8478-91.

2. Bruix J, Sherman M. Management of hepatocellular carcinoma: an update. Hepatology. 2011;53:1020-2.

3. Pawlik TM, Poon RT, Abdalla EK, Zorzi D, Ikai I, Curley SA, Nagorney DM, Belghiti J, Ng IO, Yamaoka Y, et al. Critical appraisal of the clinical and pathologic predictors of survival after resection of large hepatocellular carcinoma. Arch Surg. 2005;140:450-7; discussion 457-458.

4. Ettorre GM, Levi Sandri GB, Colasanti M, Masciana G, de Werra E, Santoro R, Lepiane $\mathrm{P}$, Montalbano M, Antonini M, Vennarecci G. Liver resection for hepatocellular carcinoma $>5 \mathrm{~cm}$. Transl Gastroenterol Hepatol. 2017;2:22.

5. Wang Z, Peng $Y$, Hu J, Wang $X$, Sun H, Sun J, Shi $Y$, Xiao $Y$, Ding Z, Yang $X$, et al. Associating liver partition and portal vein ligation for staged hepatectomy for unresectable hepatitis $b$ virus-related hepatocellular carcinoma: a single center study of 45 patients. Ann Surg. 2018.

6. Orcutt ST, Anaya DA. Liver resection and surgical strategies for management of primary liver cancer. Cancer Control. 2018;25: 1073274817744621.

7. Ramesh H. Resection for hepatocellular carcinoma. J Clin Exp Hepatol. 2014; 4:590-6.

8. Tsurusaki M, Murakami T. Surgical and locoregional therapy of HCC: TACE. Liver Cancer. 2015;4:165-75.

9. Takaki S, Sakaguchi H, Anai H, Tanaka T, Yamamoto K, Morimoto K, Nishiofuku H, Inoue M, Sueyoshi S, Nagata T, et al. Long-term outcome of transcatheter subsegmental and segmental arterial chemoemobolization using lipiodol for hepatocellular carcinoma. Cardiovasc Intervent Radiol. 2012:35:544-54

10. Makuuchi M, Thai BL, Takayasu K, Takayama T, Kosuge T, Gunven P, Yamazaki S, Hasegawa H, Ozaki H. Preoperative portal embolization to increase safety of major hepatectomy for hilar bile duct carcinoma: a preliminary report. Surgery. 1990;107:521-7.

11. Shindoh J, Vauthey JN, Zimmitti G, Curley SA, Huang SY, Mahvash A, Gupta S, Wallace MJ, Aloia TA. Analysis of the efficacy of portal vein embolization for patients with extensive liver malignancy and very low future liver remnant volume, including a comparison with the associating liver partition with portal vein ligation for staged hepatectomy approach. J Am Coll Surg. 2013;217:126-33; discussion 133-124. 
12. Schnitzbauer AA, Lang SA, Goessmann H, Nadalin S, Baumgart J, Farkas SA Fichtner-Feigl S, Lorf T, Goralcyk A, Horbelt R, et al. Right portal vein ligation combined with in situ splitting induces rapid left lateral liver lobe hypertrophy enabling 2-staged extended right hepatic resection in smallfor-size settings. Ann Surg. 2012;255:405-14.

13. Cai YL, Song PP, Tang W, Cheng NS. An updated systematic review of the evolution of ALPPS and evaluation of its advantages and disadvantages in accordance with current evidence. Medicine (Baltimore). 2016;95:e3941.

14. Dokmak S, Belghiti J. Which limits to the "ALPPS" approach? Ann Surg. 2012; 256:e6; author reply e16-17.

15. Nadalin S, Capobianco I, Li J, Girotti P, Konigsrainer I, Konigsrainer A. Indications and limits for associating liver partition and portal vein ligation for staged hepatectomy (ALPPS). Lessons learned from 15 cases at a single centre. Z Gastroenterol. 2014;52:35-42.

16. Urata K, Kawasaki S, Matsunami H, Hashikura $Y$, Ikegami $T$, Ishizone $S$, Momose Y, Komiyama A, Makuuchi M. Calculation of child and adult standard liver volume for liver transplantation. Hepatology. 1995;21: 1317-21.

17. Strasberg SM. Nomenclature of hepatic anatomy and resections: a review of the Brisbane 2000 system. J Hepatobiliary Pancreat Surg. 2005;12:351-5.

18. Zou H, Tao Y, Wang ZM. Integration of Child-Pugh score with future liver remnant yields improved prediction of liver dysfunction risk for HBV-related hepatocellular carcinoma following hepatic resection. Oncol Lett. 2017;13:3631-7.

19. Slankamenac K, Graf R, Barkun J, Puhan MA, Clavien PA. The comprehensive complication index: a novel continuous scale to measure surgical morbidity. Ann Surg. 2013;258:1-7.

20. Balzan S, Belghiti J, Farges O, Ogata S, Sauvanet A, Delefosse D, Durand F. The "50-50 criteria" on postoperative day 5: an accurate predictor of liver failure and death after hepatectomy. Ann Surg. 2005;242:824-8, discussion 828-829.

21. Yoo H, Kim JH, Ko GY, Kim KW, Gwon DI, Lee SG, Hwang S. Sequential transcatheter arterial chemoembolization and portal vein embolization versus portal vein embolization only before major hepatectomy for patients with hepatocellular carcinoma. Ann Surg Oncol. 2011;18:1251-7.

22. Ogata S, Belghiti J, Farges O, Varma D, Sibert A, Vilgrain V. Sequential arterial and portal vein embolizations before right hepatectomy in patients with cirrhosis and hepatocellular carcinoma. Br J Surg. 2006;93:1091-8.

23. Lai EC, Fan ST, Lo CM, Chu KM, Liu CL. Anterior approach for difficult major right hepatectomy. World J Surg. 1996;20:314-7; discussion 318.

24. Liu CL, Fan ST, Lo CM, Tung-Ping Poon R, Wong J. Anterior approach for major right hepatic resection for large hepatocellular carcinoma. Ann Surg. 2000;232:25-31.

25. Chang YJ, Chung KP, Chang YJ, Chen LJ. Long-term survival of patients undergoing liver resection for very large hepatocellular carcinomas. $\mathrm{Br}$ Surg. 2016;103:1513-20.

26. Cucchetti A, Cescon M, Ercolani G, Bigonzi E, Torzilli G, Pinna AD. A comprehensive meta-regression analysis on outcome of anatomic resection versus nonanatomic resection for hepatocellular carcinoma. Ann Surg Oncol. 2012;19:3697-705.

27. Jia C, Weng J, Qin Q, Chen Y, Huang X, Fu Y. Anatomic trisegmentectomy: an alternative treatment for huge or multiple hepatocellular carcinoma of right liver. Biomed Pharmacother. 2017;88:684-8.

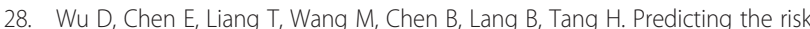
of postoperative liver failure and overall survival using liver and spleen stiffness measurements in patients with hepatocellular carcinoma. Medicine (Baltimore). 2017;96:e7864.

29. van den Broek MA, Olde Damink SW, Dejong $\mathrm{CH}$, Lang H, Malago M, Jalan $\mathrm{R}$, Saner FH. Liver failure after partial hepatic resection: definition, pathophysiology, risk factors and treatment. Liver Int. 2008;28:767-80.

30. Cieslak KP, Runge JH, Heger M, Stoker J, Bennink RJ, van Gulik TM. New perspectives in the assessment of future remnant liver. Dig Surg. 2014;31: 255-68.

31. Yamagishi $Y$, Saito H, Tada S, Horie Y, Kato S, Ishii H, Shimojima N, Haga J, Shimazu M, Kitajima M, Hibi T. Value of computed tomography-derived estimated liver volume/standard liver volume ratio for predicting the prognosis of adult fulminant hepatic failure in Japan. J Gastroenterol Hepatol. 2005;20:1843-9.

32. Zhou XP, Lu T, Wei YG, Chen XZ. Liver volume variation in patients with virusinduced cirrhosis: findings on MDCT. AJR Am J Roentgenol. 2007;189:W153-9.

33. Tong C, Xu X, Liu C, Zhang T, Qu K. Assessment of liver volume variation to evaluate liver function. Front Med. 2012;6:421-7.
34. Li J, Girotti P, Konigsrainer I, Ladurner R, Konigsrainer A, Nadalin S. ALPPS in right trisectionectomy: a safe procedure to avoid postoperative liver failure? J Gastrointest Surg. 2013;17:956-61.

35. Alvarez FA, Ardiles V, Sanchez Claria R, Pekolj J, de Santibanes E. Associating liver partition and portal vein ligation for staged hepatectomy (ALPPS): tips and tricks. J Gastrointest Surg. 2013;17:814-21.

36. Schadde E, Raptis DA, Schnitzbauer AA, Ardiles V, Tschuor C, Lesurtel M, Abdalla EK, Hernandez-Alejandro R, Jovine E, Machado M, et al. Prediction of mortality after ALPPS stage-1: an analysis of 320 patients from the international ALPPS registry. Ann Surg. 2015;262:780-5; discussion 785-786.

37. Alvarez FA, Ardiles V, de Santibanes M, Pekolj J, de Santibanes E. Associating liver partition and portal vein ligation for staged hepatectomy offers high oncological feasibility with adequate patient safety: a prospective study at a single center. Ann Surg. 2015;261:723-32.

38. Li J, Ewald F, Gulati A, Nashan B. Associating liver partition and portal vein ligation for staged hepatectomy: from technical evolution to oncological benefit. World J Gastrointest Surg. 2016;8:124-33.

39. Petrowsky H, Gyori G, de Oliveira M, Lesurtel M, Clavien PA. Is partial-ALPPS safer than ALPPS? A single-center experience. Ann Surg. 2015;261:e90-2.

40. Chan ACY, Chok K, Dai JWC, Lo CM. Impact of split completeness on future liver remnant hypertrophy in associating liver partition and portal vein ligation for staged hepatectomy (ALPPS) in hepatocellular carcinoma: Complete-ALPPS versus partial-ALPPS. Surgery. 2017;161:357-64.

41. Robles R, Parrilla P, Lopez-Conesa A, Brusadin R, de la Pena J, Fuster M, Garcia-Lopez JA, Hernandez E. Tourniquet modification of the associating liver partition and portal ligation for staged hepatectomy procedure. $\mathrm{Br} J$ Surg. 2014;101:1129-34 discussion 1134.

42. Schadde E, Clavien PA. Reply to letter: "accelerated liver hypertrophy ALPPS and more!". Ann Surg. 2015;261:e46-7.

43. Jiao LR, Fajardo Puerta AB, Gall TMH, Sodergren MH, Frampton AE: Rapid Induction of Liver Regeneration for Major Hepatectomy (REBIRTH): a randomized controlled trial of portal vein embolisation versus ALPPS assisted with radiofrequency. 2019, 11.

44. Sandstrom P, Rosok BI, Sparrelid E, Larsen PN, Larsson AL, Lindell G, Schultz NA, Bjornbeth BA, Isaksson B, Rizell M, Bjornsson B. ALPPS improves resectability compared with conventional two-stage hepatectomy in patients with advanced colorectal liver metastasis: results from a Scandinavian Multicenter Randomized Controlled Trial (LIGRO Trial). Ann Surg. 2018;267:833-40

45. Liu Y, Yang Y, Gu S, Tang K. A systematic review and meta-analysis of associating liver partition and portal vein ligation for staged hepatectomy (ALPPS) versus traditional staged hepatectomy. Medicine (Baltimore). 2019; 98:e15229.

46. Moris D, Ronnekleiv-Kelly S, Kostakis ID, Tsilimigras DI, Beal EW, Papalampros A, Dimitroulis D, Felekouras E, Pawlik TM. Operative results and oncologic outcomes of Associating Liver Partition and Portal Vein Ligation for Staged Hepatectomy (ALPPS) versus two-stage hepatectomy (TSH) in patients with unresectable colorectal liver metastases: a systematic review and metaanalysis. World J Surg. 2018:42:806-15.

47. Guiu B, Chevallier P, Denys A, Delhom E, Pierredon-Foulongne MA, Rouanet P, Fabre JM, Quenet F, Herrero A, Panaro F, et al. Simultaneous trans-hepatic portal and hepatic vein embolization before major hepatectomy: the liver venous deprivation technique. Eur Radiol. 2016;26:4259-67.

48. Hwang S, Ha TY, Ko GY, Kwon DI, Song GW, Jung DH, Kim MH, Lee SK, Lee SG. Preoperative sequential portal and hepatic vein embolization in patients with hepatobiliary malignancy. World J Surg. 2015;39:2990-8.

49. Hwang S, Lee SG, Ko GY, Kim BS, Sung KB, Kim MH, Lee SK, Hong HN. Sequential preoperative ipsilateral hepatic vein embolization after portal vein embolization to induce further liver regeneration in patients with hepatobiliary malignancy. Ann Surg. 2009;249:608-16.

50. Aloia TA, Vauthey JN. Associating liver partition and portal vein ligation for staged hepatectomy (ALPPS): what is gained and what is lost? Ann Surg. 2012;256:e9; author reply e16-19.

51. Chia DKA, Yeo Z, Loh SEK, Iyer SG, Bonney GK, Madhavan K, Kow AWC. Greater hypertrophy can be achieved with associating liver partition with portal vein ligation for staged hepatectomy compared to conventional staged hepatectomy, but with a higher price to pay? Am J Surg. 2018;215:131-7.

52. D'Haese JG, Neumann J, Weniger M, Pratschke S, Bjornsson B, Ardiles V, Chapman W, Hernandez-Alejandro R, Soubrane O, Robles-Campos R, et al. Should ALPPS be used for liver resection in intermediate-stage HCC? Ann Surg Oncol. 2016;23:1335-43. 
53. Xu C, Lv PH, Huang XE, Wang SX, Sun L, Wang FA, Wang LF. Safety and efficacy of sequential transcatheter arterial chemoembolization and portal vein embolization prior to major hepatectomy for patients with HCC. Asian Pac J Cancer Prev. 2014:15:703-6.

54. Peng PD, Hyder $\mathrm{O}$, Bloomston $\mathrm{M}$, Marques $\mathrm{H}$, Corona-Villalobos C, Dixon E, Pulitano C, Hirose K, Schulick RD, Barroso E, et al. Sequential intra-arterial therapy and portal vein embolization is feasible and safe in patients with advanced hepatic malignancies. HPB (Oxford). 2012;14:523-31.

55. Liu L, Ren ZG, Shen Y, Zhu XD, Zhang W, Xiong W, Qin Y, Tang ZY. Influence of hepatic artery occlusion on tumor growth and metastatic potential in a human orthotopic hepatoma nude mouse model: relevance of epithelial-mesenchymal transition. Cancer Sci. 2010;101:120-8.

56. Tsai WL, Liang PC, Chen $\mathrm{CH}$. Tumor lysis syndrome after transarterial chemoembolization plus portal venous embolization for hepatocellular carcinoma. J Formos Med Assoc. 2012:111:724-5.

57. Jiang RD, Jian WC, Jin N, Zhang ZL, Li T. Tumor lysis syndrome: a serious complication of transcatheter arterial chemoembolization for hepatocellular carcinoma. Am J Med. 2016;129:e173-6.

58. Yoshida H, Mamada Y, Taniai N, Uchida E. Spontaneous ruptured hepatocellular carcinoma. Hepatol Res. 2016;46:13-21.

59. Zhu Q, Li J, Yan JJ, Huang L, Wu MC, Yan YQ. Predictors and clinical outcomes for spontaneous rupture of hepatocellular carcinoma. World J Gastroenterol. 2012;18:7302-7.

\section{Publisher's Note}

Springer Nature remains neutral with regard to jurisdictional claims in published maps and institutional affiliations.

Ready to submit your research? Choose BMC and benefit from:

- fast, convenient online submission

- thorough peer review by experienced researchers in your field

- rapid publication on acceptance

- support for research data, including large and complex data types

- gold Open Access which fosters wider collaboration and increased citations

- maximum visibility for your research: over $100 \mathrm{M}$ website views per year

At $\mathrm{BMC}$, research is always in progress.

Learn more biomedcentral.com/submissions 